\title{
PROMOÇÃO DA SAÚDE NA ESCOLA: A LUDICIDADE MULTIPLICANDO SABERES
}

Luiz Rogério Romero, Giovanni Henrique Quizzini, Márcia Regina Canhoto de Lima, José Milton de Lima

Universidade Estadual Paulista - UNESP. Curso de Educação Física, Presidente Prudente - SP. E-mail: romero@fct.unesp.br

\section{RESUMO}

O cenário de saúde no Brasil tem apresentado várias mudanças nos últimos anos, com destaque para as doenças não transmissíveis. Neste sentido, a realização de atividades físicas recebe amplo incentivo, seja no âmbito científico ou na sociedade em geral. Assim, a escola tem sido apontada como ambiente adequado para o estímulo dessas práticas e demais comportamentos de saúde. 0 presente trabalho objetiva retrata um projeto de pesquisa e extensão que contempla a ludicidade como meio para a promoção da saúde na infância. A metodologia adotada caracteriza-se como pesquisa-ação, desenvolvida em uma escola pública do oeste paulista. Enfatiza-se a discussão de possibilidades metodológicas para vivências das atividades lúdicas no interior e fora da escola como estratégia de saúde. Relata-se também a necessidade de adoção de suportes teóricos e estruturais que favoreça toda a comunidade escolar, incluíndo os pais ou responsáveis das crianças, quanto às práticas, aos conhecimentos e atitudes positivas à saúde.

Palavras-chave: Estudantes; Ludicidade; Saúde; Infância; Educação Física.

\section{HEALTH PROMOTION IN SCHOOL: THE PLAYFULNESS MULTIPLYING KNOWLEDGE}

\begin{abstract}
The health scenario in Brazil has experienced many changes in recent years, with emphasis on non-communicable diseases. In this sense, the physical activities receive ample encouragement, either in the scientific or society in general. Thus, the school has been identified as an appropriate environment for the encouragement of such practices and other health behaviors. The present paper portrays a research project that includes the extension and playfulness as a means of promoting health in childhood. The methodology is characterized as action research, undertaken in a public school west of São Paulo. Emphasizes the discussion of methodological possibilities for experiencing the fun activities inside and outside the school as a health strategy. It is also reported the need for adoption of theoretical and structural supports that encourages whole school community, including parents or guardians of children in the practical, knowledge and positive attitudes to health.
\end{abstract}

Keywords: Students; playfulness; health; childhood; Physical education. 


\section{INTRODUÇÃO}

A saúde da população brasileira tem apresentado significativas mudanças no perfil epidemiológico. A diminuição das moléstias infectocontagiosas e o predomínio das doenças crônico-degenerativas têm sido evidenciados na atualidade (GONÇALVES et al, 1997). Este advento encontra reforço na diminuição da mortalidade infantil e elevação da expectativa de vida ao nascer (IBGE, 2008).

Desse modo, recorrentes ações de saúde, subsidiadas por estudos científicos, destacam a relevância da atividade física no enfrentamento dos males não transmissíveis e fatores de risco em elevação na sociedade moderna (PEREIRA, 1995). Embora estas afirmações enfatizem o cenário biológico dos benefícios do estilo de vida ativo, suas contribuições podem transcender os aspectos físicos e contribuir no panorama psicológico, afetivo, social (COSTA; SOARES; TEIXEIRA, 2007).

Diversos estudos tem apontado a relação entre elevação do nível de atividade física e a prática de outros comportamentos positivos à saúde, como alimentação saudável, menor consumo de álcool, tabaco e outras drogas (SASCO et al., 2003).

Neste sentido, a escola vem sendo reconhecida como cenário privilegiado para a promoção da saúde e também no desenvolvimento de hábitos e práticas saudáveis, entendendo as aulas de Educação Física como espaço fundamental nestas ações. (BRASIL, 2007; GUEDES; GUEDES, 2001). Estima-se que o acesso à escola no Brasil seja superior a 95\% na educação básica (IBGE, 2013a).

Miranda (2006) ressalta o papel da escola na sociedade e, em especial da Educação Física escolar como área de conhecimento que trata das atividades corporais, de movimento e dos conhecimentos relacionados na promoção da saúde e qualidade de vida. Enfatiza ainda que para muitas crianças a escola, considerando as mudanças de natureza: social, econômica e cultural se transformou em um ambiente indispensável para sua prática corporal, podendo assim contribuir para contemplar a função de colaboradora no aumento da atividade física e de aquisição de hábitos saudáveis e diminuição do sedentarismo na infância e juventude.

No entanto, o cenário observado nem sempre demonstra participação positiva da escola na promoção da atividade física e saúde. Pesquisa com amostra nacional sobre atividade física de escolares apresentam dados preocupantes. Dentre os estudantes avaliados, cerca de $70 \%$ não atendem as recomendações de atividade física acumulada na semana. A situação é ainda mais agravante para a população feminina, considerando que apenas $21,8 \%$ relataram acumular 300 minutos de atividades físicas na semana (IBGE, 2013b). 
Soma-se os dados preocupantes de crescimento da obesidade entre crianças na faixa etária de 05 a 09 anos no período entre 1989 a 2009, referindo aumento de 12,5\% para os meninos e 9,4\% para o sexo feminino.

Desta forma, proporcionar situações que possibilitem a realização de atividades físicas na escola, assim como a aumento do interesse por essas práticas de maior elevação do gasto energético são urgentes e estão apoiadas nas orientações oficiais.

Entre os escolares, a utilização da ludicidade pode promover o gosto pelos conteúdos da Educação Física e incentivar a aquisição de conhecimentos a respeito do corpo, de suas potencialidades e especialmente na sua manutenção saudável.

Dessa maneira, o objetivo deste estudo foi o de analisar os relatos de alunos do curso de Educação Física bolsistas de projeto de Extensão e de iniciação à docência sobre a implementação da ludicidade nas aulas de Educação Física e suas contribuições para a promoção da saúde.

\section{METODOLOGIA}

A pesquisa tem sido desenvolvida junto ao projeto de extensão "Multiplicando Saberes: Ludicidade e Qualidade de Vida na Infância", vinculado ao Departamento de Educação Física da Faculdade de Ciências e Tecnologia da UNESP, Presidente Prudente-SP. Articula-se ao subprojeto intitulado "A formação de professores de Educação Física para a Educação Básica a partir da interlocução entre infância, juventude e cultura corporal de movimento" (PIBID), vinculado ao Curso de Educação Física da FCT/UNESP/PP.

Parte do pressuposto de que a ludicidade representa um recurso privilegiado da Educação Física contemporânea na busca da aquisição, por parte dos alunos dos anos iniciais do ensino fundamental, de hábitos voltados à saúde e a melhoria da qualidade de vida.

Neste sentido, o projeto contribui na multiplicação de conhecimentos sobre os benefícios que as atividades lúdicas promovem na vida das crianças. Também, favorece a reflexão sobre a melhoria da qualidade de vida e o fortalecimento do potencial de saúde das crianças na perspectiva da ludicidade.

Para atender aos objetivos propostos, a pesquisa adotou a metodologia qualitativa de Pesquisa-ação. Desse modo, compreende-se que:

Qualitativo está ligado aos sentidos produzidos nas relações sóciohistoricamente determinadas, afirmando a alteridade e as turbulências que nos movem a analisar, a dialogar, a buscar entender o que vivemos. As palavras mudam de significado em função dos sentidos que vão sendo agenciados nas práticas de acordo com as relações de força implicadas naquele momento (ROCHA, 2006, p.171). 
Segundo THIOLLENT (2005, p.16) é um tipo de pesquisa social com base empírica concebida e realizada em estreita associação com uma ação ou com a resolução de um problema coletivo. Nesta modalidade de pesquisa pesquisadores e os participantes representativos da situação ou do problema estão envolvidos de modo cooperativo ou participativo.

Desenvolve-se o trabalho em uma instituição de Ensino Fundamental no Município de Presidente Prudente-SP, na qual, participam aproximadamente 220 crianças na faixa etária entre seis e onze anos.

São organizadas reuniões semanais de planejamento entre o professor da escola, estudantes de licenciatura em Educação Física e professores coordenadores do projeto. Nestes encontros formula-se as inserções da ludicidade nos planos de aula. Também se destina o período de investigação da literatura no aprofundamento da ludicidade, infância e Educação Física Escolar, com discussão posterior com todos os professores e coordenadores do projeto. Em seguida, se desenvolve as aulas na escola. Após realização, o grupo se reúne para avaliar as ações realizadas e planejar as atividades da semana seguinte. Dessa forma, se observa a participação dos alunos nas aulas de Educação Física. Os alunos universitários participantes do projeto realizam registros escritos de todos os momentos do trabalho para análise. Este procedimento decorre todo o primeiro semestre de 2014.

\section{RESULTADOS}

A escola possui amplo espaço, com duas quadras poli-esportivas, sendo apenas uma coberta e dez salas de aulas.

O primeiro contato com os alunos foi de apresentação. Os alunos demostraram interesse e expectativas pelas atividades propostas. Dentre elas, a brincadeira "boneca de lata", com enfoque na movimentação, consciência corporal e lateralidade. Na segunda intervenção, as crianças nos receberam com entusiasmo pela nossa presença e pelas atividades combinadas. A cada semana, novas intervenções são feitas repetindo as atividades que os alunos gostam e contemplando novas, ampliando assim a cultura lúdicas das crianças. A participação das crianças está intensa podendo se observar a motivação pela atividade.

Percebemos que no intervalo as crianças jogam e brincam nos espaços destinados as atividades. Percebemos que grande parte das crianças não comem a merenda orientada por nutricionistas. Optam por trazer de casa alimentos industrializados e ricos em gordura. Esta situação está em análise pelo grupo e comunidade escolar, assim como posterior inserção de reflexões sobre os benefícios da alimentação saudável. 
Neste semestre de trabalho, percebemos a relevância do planejamento das ações em Educação Física Escolar, visando aos objetivos do projeto. Acompanhar o dia-a-dia do professor, situações reais de aula e sistematização de conhecimentos contribui significativamente para a formação dos alunos do Curso de Educação Física. Também destaque para aulas que vão além da prática pela prática e que promovem a ampliações de conhecimentos e repertório dos participantes. Valoriza-se nesta perspectiva, o planejamento e a preparação prática e teórica do profissional de Educação Física, apoiados nas suas experiências no trabalho, na literatura e discussão no grupo do projeto.

\section{DISCUSSÃO}

Ressaltamos a efetiva participação dos alunos nas atividades em que o lúdico foi privilegiado. Não se trata de apenas realizar determinados movimentos demonstrados pelo professor, mas sim recriar situações, estratégias e vivências corporais prazerosas, motivantes e interativas. Esta abordagem supera a expectativa de aumento do gasto energético, benefícios biológicos e diminuição dos fatores de riscos associados à prática de atividades físicas. Proporciona a consciência corporal, autoconhecimento, ampliação de possibilidades da manifestação da cultura corporal e as benesses do estilo de vida ativo.

Estas vivências corporais e de aprendizagem significativa pode contribuir para manutenção nas fases seguintes da vida de atividades físicas, outros hábitos saudáveis e de qualidade de vida.

Infelizmente a prática corporal, pautada em uma perspectiva lúdica (AYRES; SENA, 2010), vem ocupando posição secundária nas escolas, que focam e privilegiam a alfabetização da leitura e da escrita e dos conhecimentos lógico-matemáticos. Pesquisa realizada por Lima (2008) com alunos pré-escolares constatou que, mesmo nesta modalidade educacional, a brincadeira está cada vez mais secundarizada e substituída por "lições" e tarefas. Até mesmo para as crianças as atividades lúdicas são cada vez mais negadas no cotidiano escolar.

Sobretudo, entendemos que muitas outras variáveis e determinantes atuam neste segmento, como condições estruturais, socioeconômicas, oferta pública de oportunidades de atividades físicas e de lazer. Assim, a organização do espaço escolar de modo incentivador do movimento e de vivências corporais pode auxiliar no despertar de interesse pela atividade física e promoção da saúde. 


\section{CONCLUSÃO}

Dessa forma, considera-se que a implementação de, pelo menos, três aulas na semana poderia oportunizar melhores condições de atividades físicas para à saúde. A limitação quanto ao número de aulas também foi evidenciado em outros estudos (IBGE, 2013b). Doravante, deve-se considerar a qualidade dessas intervenções referente à saúde (GUEDES, 1999), como elaboração adequada de planos de aula, embasamento teórico docente e com o protagonismo dos alunos envolvidos. Defendemos, também, que é necessário ampliar o tempo de intervalo das crianças, incentivando e oportunizando mais tempo para que realizem atividades físicas entre si, de forma livre ou mesmo orientada.

Outro ponto decorre a estrutura física e organização da instituição escolar que favoreça a utilização de espaços para o exercício da ludicidade.

O presente projeto apresenta dados preliminares, porém demonstra que a ludicidade pode ser considerada importante ferramenta para o estímulo de atividades físicas e promoção da saúde.

\section{REFERÊNCIAS}

AYRES, J. S.; SENA, S.S. A importância do lúdico na Educação Infantil: fundamentação teórica. Caderno Multidisciplinar de Pós - Graduação da UCP. Pitanga, v.1, n.1, p. 106-121, jan.2010.

BRASIL, Ministério da Saúde; Ministério da Educação. Programa Saúde na escola - PSE, 2007. Disponível em < http://dab.saude.gov.br/portaldab/pse.php> Acesso em: 11 jun. 2013.

COSTA, R.; A.; SOARES, H.L.R.; TEIXEIRA, J.A.C. Benefícios da atividade física e do exercício físico na depressão. Rev. Dep. Psicol., UFF, Niterói , v. 19, n. 1, 2007.

FREITAS JR. IF. Padronização de Técnicas Antropométricas, 1ำ ed. São Paulo: Cultura Acadêmica, 2009.

GONÇALVES, A. et al. Saúde coletiva e urgência em educação física. Campinas. Papirus. 1997. $190 p$.

GUEDES, D.P. \& GUEDES, J.E.R.P. Crescimento, composição corporal e desempenho motor de crianças e adolescentes. São Paulo, CLR Baileiro, 1997.

GUEDES, D.P. Educação para a Saúde Mediante Programas de Educação Física. São Paulo: revista motriz, v. 5, n. 1, p. 10-14, jun. 1999.

GUEDES, D.P.; GUEDES J.E.R.P. Esforços físicos nos programas de educação física escolar. Rev Paul Educ Fis. v.15, n.1. pp. 33-44, 2001. 
INSTITUTO BRASILEIRO DE GEOGRAFIA E ESTATÍ́STICA - IBGE. Diretoria de Pesquisas, Coordenação de População e Indicadores Sociais, Projeção da População do Brasil por Sexo e Idade para o Período 1980-2050 - Revisão 2008. Disponível em <http://brasilemsintese.ibge.gov.br/populacao/taxas-de-mortalidade-infantil>. Acesso 23 set. 2014.

INSTITUTO BRASILEIRO DE GEOGRAFIA E ESTATÍ́STICA - IBGE. Pesquisa Nacional por Amostra de Domicílios. Rio de Janeiro. v. 32, 2013a. Disponível em

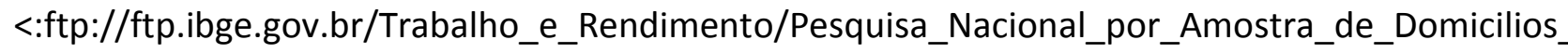
anual/2012/Volume_Brasil/pnad_brasil_2012.pdf>. Acesso em 19 ago. 2014.

INSTITUTO BRASILEIRO DE GEOGRAFIA E ESTATÍSTICA - IBGE. Pesquisa Nacional de Saúde do Escolar (PeNSE) 2012. Rio de Janeiro: IBGE, 2013. Disponível em<: http://www.ibge.gov.br/home/estatistica/populacao/pense/2012/pense_2012.pdf>. Acesso em 23 set. $2013 b$.

LIMA, J. M. O jogo como recurso pedagógico no contexto educacional. São Paulo: Cultura Acadêmica: Universidade Estadual Paulista, Pró-reitora de Graduação, 2008.

MIRANDA, M. J. Educação Física e saúde na escola. Estudos. Goiânia, v.33, p. 643-653, jul/ago, 2006.

PEREIRA, M. G. Epidemiologia: teoria e prática. Rio de Janeiro: Guanabara Koogan, 1995. 596p.

ROCHA, M. L. Psicologia e as práticas institucionais: A pesquisa-intervenção em movimento. Psico. Porto Alegre:, v. 37, n. 02, p. 169-174. 2006.

SASCO, A.J. et al. Trends in Tobacco Smoking Among Adolescents in Lion, France. Eur. J. Cancer. v. 39, p. 496-504, 2003.

THIOLLENT, M. Metodologia da Pesquisa-ação. 14ạ edição. São Paulo: Editora Cortez, 2005. 